\title{
Do Ritornelo a Lugar nenhum
}

\section{From Ritornelo to Lugar nenhum}

Zilá Maria Muniz 


\section{Resumo}

Este estudo relaciona os conceitos de Ritornelo e Fabulação como suporte para refletir sobre a dramaturgia e a articulação do material desenvolvido ao longo dos ensaios na montagem do espetáculo Lugar nenhum do Ronda Grupo. O Ritornelo conceito desenvolvido por Gilles Deleuze e Felix Guatarri, apresenta o movimento circular operado por seus três aspectos, o que direcionou de forma precisa o trabalho como a sensação, a percepção e a memória, aspectos fundamentais no processo de composição. Discute a ética da experimentação do abandono, daquilo que tenciona a fuga, fazendo da filosofia uma pragmática de dispersão contínua e da dança outro eixo de experimentação. Por fim, descreve como as possibilidades de circular pelas histórias pessoais e pelas sensações, do que estas fazem com o movimento no momento que é dançado e as imagens, que são primordialmente internas ao longo do processo de criação, transbordaram para a cena.

Palavras-chave: Composição coreográfica, dramaturgia, processo de criação

\section{Abstract}

This study relates the concepts of Ritornelo and Fabulation as support to reflect on the dramaturgy and the articulation of material developed over the rehearsals in assembling the dance piece of Lugar nenhum of Ronda Grupo. Ritornelo a concept developed by Gilles Deleuze and Felix Guattari, presents the circular motion operated by its three aspects, which directed precisely the use of sensation, perception and memory, key aspects in the composition process. It discusses the ethics of experimentation of abandonment, of that which does it intend to flight, making a pragmatic philosophy of continuous dispersion and dance another experimentation axis. Finally, describes how the circular possibilities among the personal stories and the sensation, and what these do with the movement when it is danced and the images, which are primarily built during the process of creation and then, overflowed to the scene.

Keywords: Composition, dramaturgy, choreography

ISSN: 1414.5731

E-ISSN: 2358.6958

${ }^{1}$ Doutora em Teatro, Coreógrafa e Diretora do Ronda Grupo.

zilamuniz@hotmail.com 
Do lugar onde estou já fui embora...

(Manuel de Barros)

Uma criança no escuro, tomada de medo, tranquiliza-se cantarolando. Ela anda, ela para, ao sabor de sua canção. Perdida, ela se abriga como pode, ou se orienta bem ou mal com sua cançãozinha. Esta é como o esboço de um centro estável e calmo, estabilizador e calmante, no seio do caos. Pode acontecer que a criança salte ao mesmo tempo que canta, ela acelera ou diminui seu passo; mas a própria canção já é um salto: a canção salta do caos a um começo de ordem no caos, ela arrisca também deslocar-se a cada instante. Há sempre uma sonoridade no fio de Ariadne. Ou o canto de Orfeu (Deleuze e Guatarri, 1997, p. 115).

A partir do conceito Ritornelo de Gilles Deleuze e Felix Guattarri, citado nos livros Mil Platôs (1997) e O que é a filosofia? (1993), que encontrei uma maneira de "racionalizar", ou seja, o Ritornelo me serviu como metáfora para pensar a improvisação como uma experiência de estar no mundo presente na criação. Encontrei também no conceito do Ritornelo suporte para refletir sobre as costuras e a articulação do material desenvolvido ao longo dos ensaios na montagem do espetáculo Lugar nenhum. O Ritornelo direcionou de maneira precisa a forma como os colaboradores e eu lidamos com a sensação, a percepção e a memória, aspectos que foram fundamentais no desenvolvimento do trabalho de composição.

Com duração de 60 minutos, Lugar nenhum foi produzido pelo Ronda Grupo em 2010 por meio do Prêmio Funarte de Dança Klauss Vianna 2009. A direção e a concepção do trabalho foram minhas e a criação foi em colaboração entre o núcleo criativo do grupo: os bailarinos Egon Seidler, Karina Degregório, Letícia Martins, Nastaja Brehsan, Paula Bittencourt e Vicente Mahfuz; cenário e objetos de cena de Ana $\mathrm{Pi}$; iluminação de Marcos Klann; e design gráfico de Lena Muniz. A trilha sonora é de Marcelo Muniz, no piano, improvisado a partir de músicas do repertório de Cartola. A estreia do espetáculo aconteceu em Setembro de 2010 em Florianópolis (SC).

Lugar nenhum explora a ideia de que uma possibilidade de vida se avalia nela mesma pelos movimentos que ela traça e pelas intensidades que ela cria. Interessounos pesquisar como um corpo encontra diferentes estados ao improvisar e como se dá, durante o improviso, o desencadeamento de sensações e impressões, a criação de imagens e a dissipação dessas imagens para dar lugar a outras sensações que desencadearão outras impressões e assim por diante. Tudo ocorre numa zona de tensão que permanece o tempo todo para, assim, intensificar os momentos de potencia e exploração dos estados. As sensações que evocam esses estados constituem a afirmação nostálgica da memória. Lugar nenhum nos aconteceu como um desafio no sentido de que nós nos propusemos a colecionar um repertório de movimentos, ações e gestos, para então desenvolver padrões e pequenos eventos que seriam definidos para cada cena e improvisados durante cada apresentação, sem uma sequência ou ordenação de coreografia fixada. 


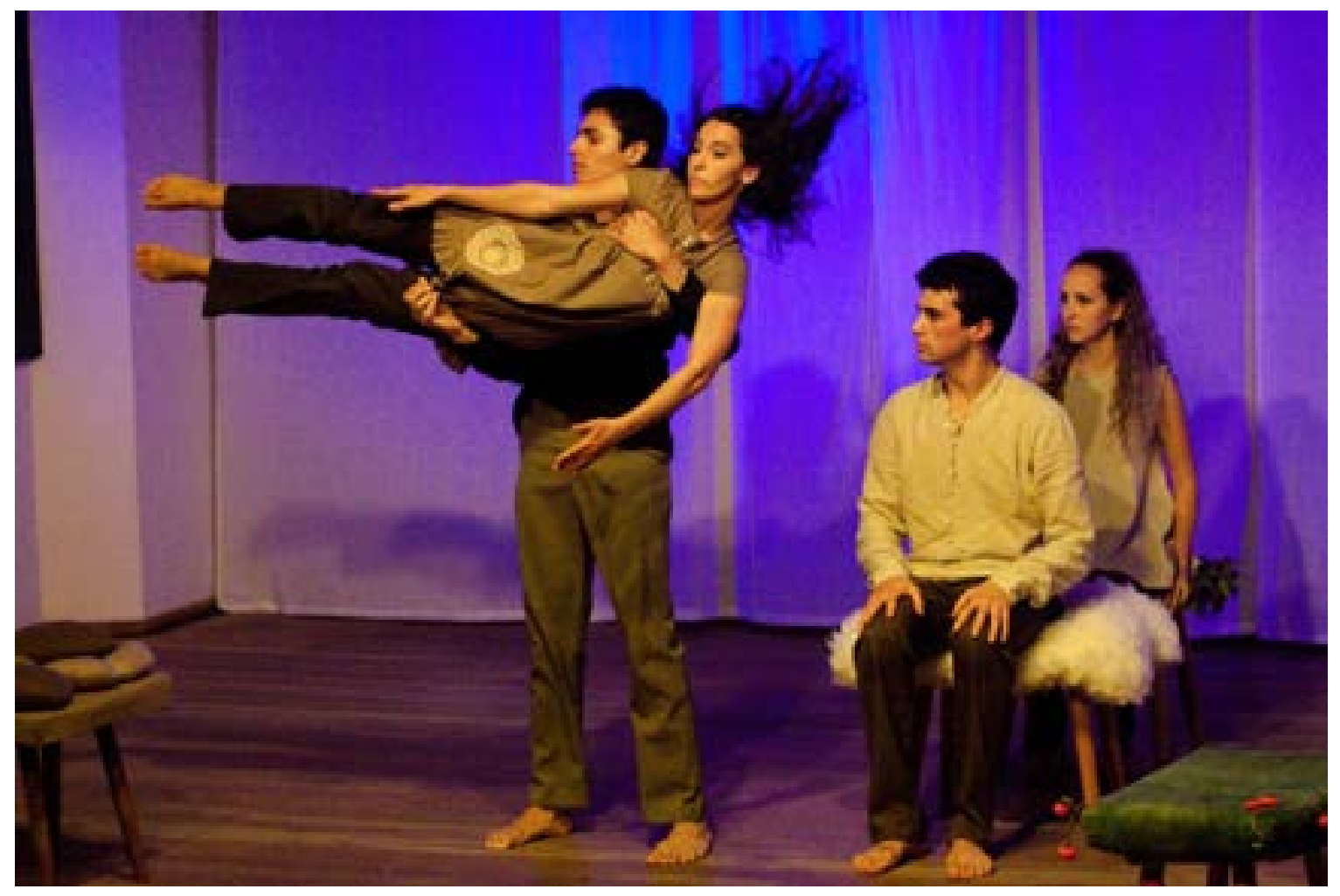

Lugar nenhum - Letícia Martins, Vicente Mahfuz e Egon Seidler Foto: Cristiano Prim

A movimentação que desenvolvemos e é dançada em Lugar nenhum consiste em padrões de movimento, movimentos isolados e gestos que colecionamos ao longo do processo. Esse material surgiu por meio da exploração de histórias e de sensações que a memória trazia de cada cena e de cada intérprete - quatro intérpretes para quatro cenas. Essas histórias pessoais foram visitadas inúmeras vezes, tanto pelo movimento que as sensações estimularam no corpo de cada um ou, ainda, pela maneira que as coleções de movimentos, gestos e ações se transformavam em eventos entre dois ou mais bailarinos. No entanto, as visitas às histórias pessoais não se dão no plano figurativo e também ocorrem sem uma narrativa linear. Além do material próprio de cada bailarino existe o material que foi incorporado, originado dos outros três. É interessante pensar em como se deu e se dá, em cada apresentação, essa apropriação e como se desenvolvem as relações entre esse material que, por assimilação, é transformado e se apresenta para o outro conectado no todo.

O Ritornelo vai provocar as noções sobre os modos em que os procedimentos de criação de material foram se desencadeando, o que inicialmente não estava claro. O que fazer com aquele repertório de gestos e com as coleções de movimentos? Para onde esse material nos direcionava? No momento em que nos demos conta de como as sensações provenientes das histórias e compartilhadas geravam uma dinâmica de relações, o Ritornelo se tornou a chave para compreender e reconhecer as técnicas de criação que estávamos originando e, consequentemente, dar sentido para como as relações se transformavam em um evento coreográfico.

Portanto, o que é o Ritornelo? O conceito de Ritornelo, para Deleuze e Guattarri (1997), se constitui a partir de duas éticas: "a ética da experimentação" e a "ética da 
prudência necessária". A tensão entre estas faz com que se possa pensar num terceiro ethos, característica comum a um grupo de indivíduos pertencentes a uma mesma sociedade que é "a ética do improviso" que, ao incorporar a experimentação e a prudência necessária, improvisa continuamente outra(s) modalidade(s) de existência

É possível pensarmos na improvisação como processo de composição em forma contínua de existência e fenômeno processual e que, por conseguinte, congrega a ética da improvisação frente a uma plateia. A ética do improviso passa a ser a própria experimentação criativa, o uso, a prática, a pragmática propriamente dita. $\mathrm{A}$ ética, portanto comporta a própria experimentação do abandono, daquilo que tenciona a fuga, fazendo da filosofia uma pragmática de dispersão contínua e da dança outro eixo de experimentação. De acordo com Deleuze e Guatarri, o Ritornelo está totalmente ligado ao problema do território, da saída ou da entrada no território, se relaciona ao problema da territorialização e da desterritorialização. É a articulação entre os elementos conhecidos e os aspectos desconhecidos de um repertório ou de espaços estranhos, entrar e sair da zona de conforto, vislumbrar as possibilidades de criação inéditas e surpreendentes por meio da experiência pura de estar no momento. Da mesma forma, vislumbramos as possibilidades de circular pelas sensações, entrando e saindo de sensações e do que estas fazem com o movimento no momento que é dançado.

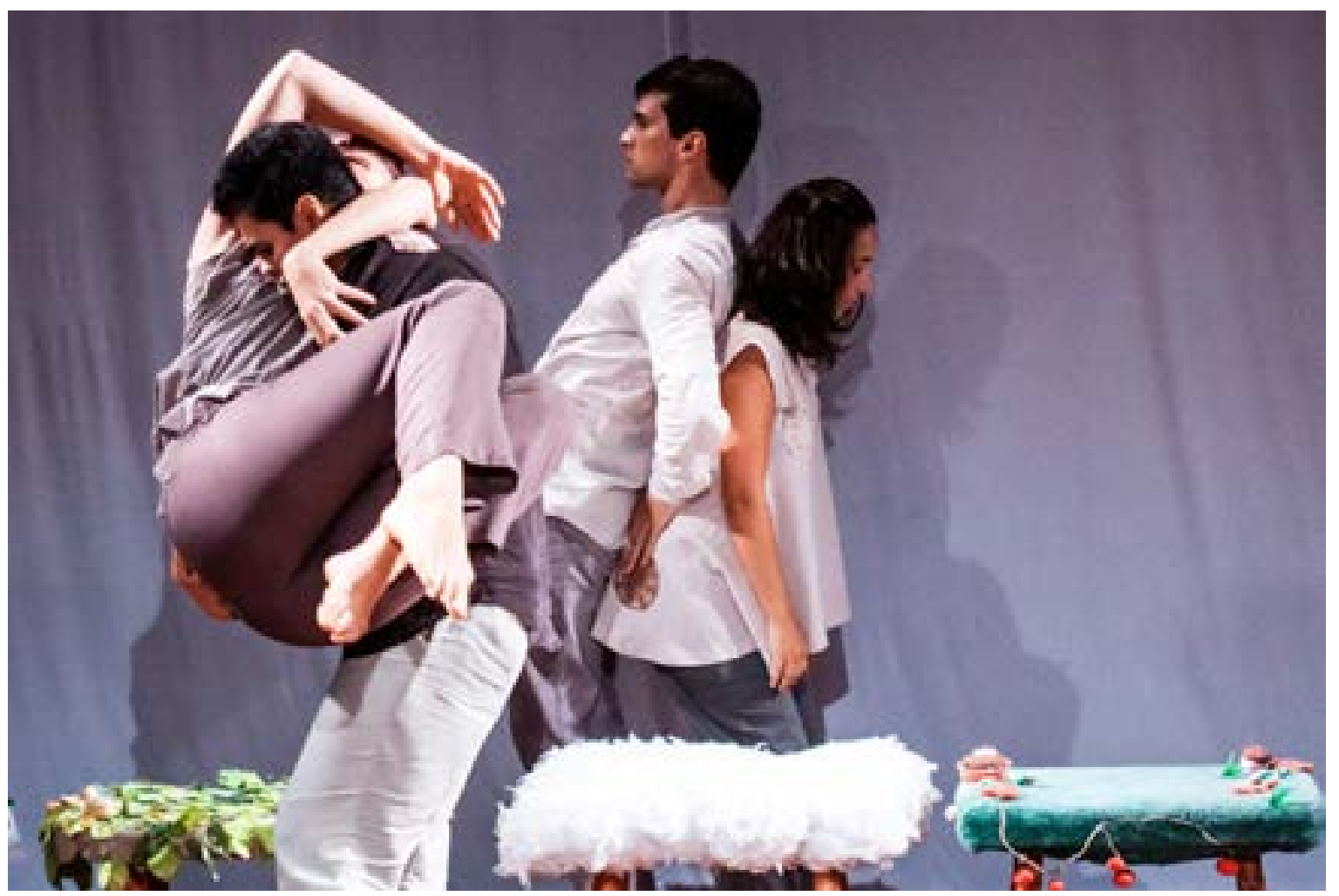

Lugar nenhum - Nastaja Brehsan, Egon Seidler, Vicente Mahfuz e Karina Degregório Foto: Cristiano Prim

Segundo Deleuze e Guattari (1997), um Ritornelo está sempre em relação com outros Ritornelos. O que o define, primeiramente, é que parte do caos em busca de um território, de um plano de imanência a um agenciamento territorial, como um componente direcional, para então se organizar esse agenciamento e se traçar um 
território em torno do ponto do centro, ou seja, em torno de um eixo, como um componente dimensional.

Ao improvisar, Lugar nenhum se relaciona à percepção que evoca a memória sobre situações em que o protagonista da dança é a sensação, é ela que faz o corpo dançar em relação também ao corpo do outro e as conexões se constroem. Durante toda e a cada apresentação os quatro bailarinos nunca deixam o espaço de cena, a presença é constante e as linhas de tensão que são criadas fazem com que cada pequeno movimento que aconteça seja percebido por todos. Sair e entrar na sensação, pelo movimento ou por meio da memória, e na potência do momento presente o agenciamento territorial se estabelece. No caso aqui, são as sensações que as histórias pessoais engatilharam no bailarino desde a sua concepção, em direção a outros agenciamentos que são as sensações das histórias dos outros. Essa é a operação das linhas de fuga que partem em direção a outros territórios e colocam o território como uma instância provisória. Um território que é transitório, onde se dão os agenciamentos como um componente de passagem, de fuga. O depoimento abaixo expõe esses aspectos do processo de criação de Lugar nenhum:

Primeiro através da memória, no resgate das histórias. Acessar uma informação vivida é pra mim vive-la novamente de outra forma, com outro olhar e recorte, um resgate de estados latentes no corpo. A segunda etapa teve a ver com o desdobramento destes estados, em movimento e dança. Estes movimentos sequenciados, não contavam a narrativa, mas produziam forças, tensões, ritmos, que geravam novas leituras. Entretanto toda a cena era estruturada também levando a história de cada um como base. Na minha cena, eu passava mais da metade do tempo de costas, trazendo para cena um estado de "ofuscamento" em que eu vivi na infância, entretanto, não dizia isso... tudo é muito subjetivo e explicito ao mesmo tempo... Eu me sentia rasgando o corpo nos estados em que cada cena me colocava, mas o que chegava para o publico eram as relações que os corpos geravam, as interações, as tensões, a leveza, a maldade, a briga, o julgamento... enfim... conceitos, estados, emoções, tudo estava ali sem ser dito em palavras, mas em vivência (Nastaja Brehsan em depoimento, fevereiro de 2014).

Enquanto trabalhávamos no processo de criação, buscamos sempre aplicar ou desenvolver o devir dança por meio do conceito de Ritornelo que, segundo Deleuze e Guatarri, implica na coexistência de três componentes, dinamismos ou etapas. Simultaneamente acontecem: em primeiro lugar existe o componente direcional, da ordem do ponto como uma primeira manifestação frente ao caos; num segundo momento há o componente dimensional, quando se busca o território e sua consolidação; por fim, há o componente de passagem ou de fuga que faz com que o território esteja sempre em variação.

A partir dessa concepção, no processo compositivo o que propus como o eixo foi a sensação que nos remete prontamente à memória, como que envolvendo esse eixo e traçando um território, e finalmente as linhas de fuga que são as percepções que nos fazem criar impressões e que nos conduzem a outras sensações. Lugar nenhum é um trabalho que se distingue por seu caráter de improvisação sem a marcação de tempo ou espaço definida e fixada, o material desenvolvido para cada cena se apresenta por meio do desencadeamento de eventos, o que pode se repetir ou não na próxima apre- 
sentação ou ensaio. Portanto, é possível experimentar durante as apresentações e criar novos eventos que podem vir a ser incorporados ou não posteriormente.

$\mathrm{Na}$ "ética da experimentação", o Ritornelo apresenta o movimento circular operado por seus três aspectos. Segundo Deleuze e Guatarri (1997), isso aponta sempre na possibilidade de fuga do risco da improvisação, da territorialização e da desterritorialização, dos riscos que tal movimento implica. Acredito nos elementos do Ritornelo como uma forma de fazer referência aos elementos conhecidos e desconhecidos da improvisação, nas linhas de fuga como movimento de passagem e de transitoriedade. Isso ocorre na invenção que a todo instante conduz por territórios desconhecidos e, fundamentalmente, remete à ideia de processo característica da improvisação.

A "ética da prudência necessária", de Deleuze e Guatarri (1997), diz respeito à formação de uma política, de uma prática em que a relação do indivíduo com si mesmo se dá sem a necessidade de recorrer a verdades interiores, pré-concebidas e programadas, em que as linhas de fuga são as grandes condutoras do movimento. Uma prática que busca encontrar alternativas às formas de assujeitamento, apontando para o campo dos processos criativos, daquilo que insistentemente se desprende e dita outra composição possível. É seguida de um componente estético, numa estética que é a prática de novos estilos de vida, escapando aos regimes de poder e saber. Dessa forma, cria novas maneiras de ver e estar no mundo, de se relacionar com a instabilidade, consciente das possibilidades dessa interdependência entre o eu e o mundo.

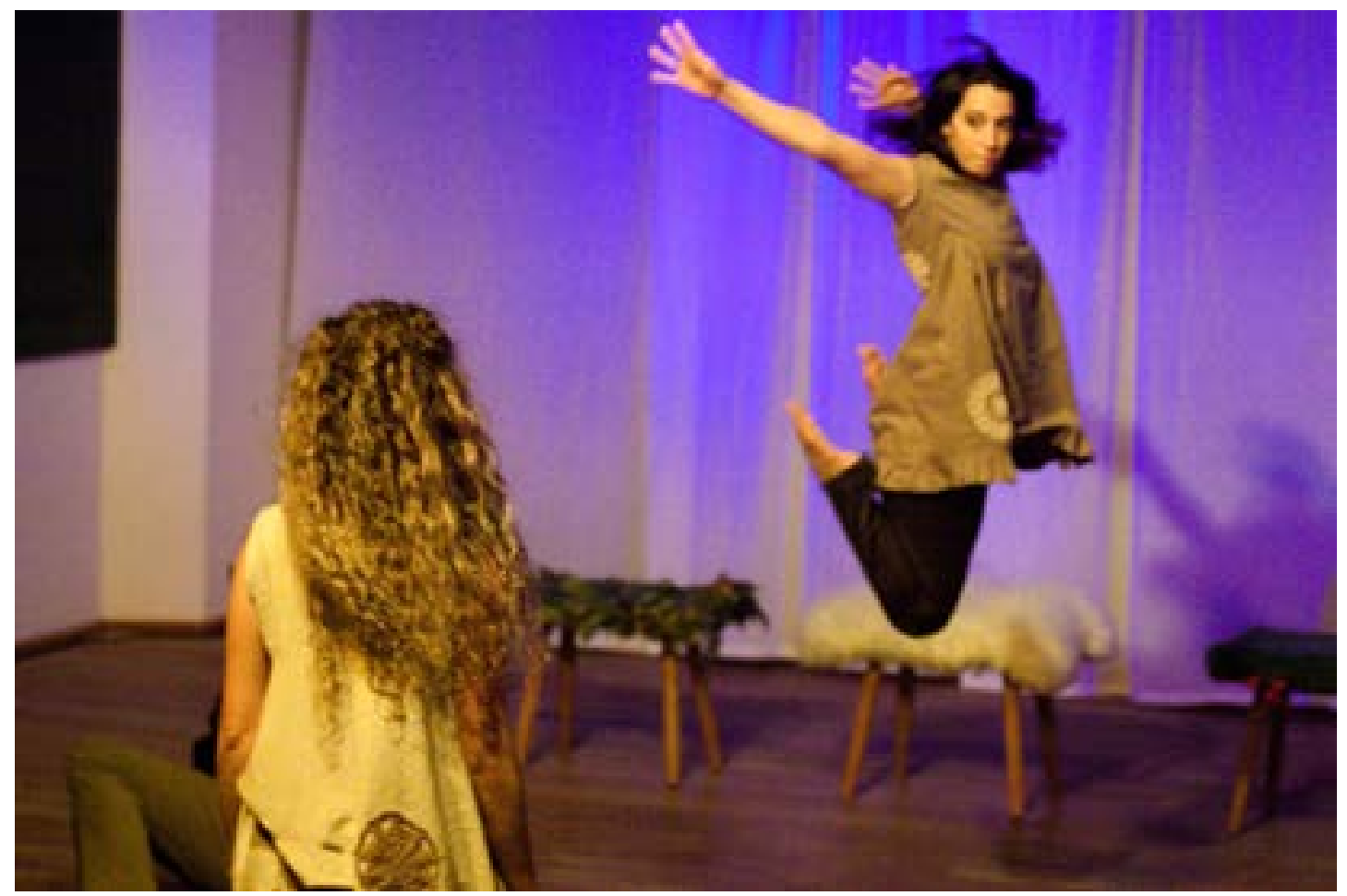

Lugar nenhum - Letícia Martins e Karina Degregório Foto: Cristiano Prim

Com a improvisação é possível desenvolver um senso de responsabilidade por meio da habilidade de estar presente no mundo e estar presente em si mesmo. Com isso, as possibilidades de criar e executar, passear por lugares onde já pertencemos e 
algumas vezes inauguramos, mas que, de acordo com a "teoria do eterno retorno" de Nietzsche, coloca a existência estética como a mais elevada necessidade. "Esta vida, tal qual a vives atualmente, é preciso que a revivas ainda uma vez e uma quantidade inumerável de vezes" (Nietzsche, 2002, aforismo 341, p. 223). Nesse sentido, no exercício de composição para Lugar nenhum, pergunto: o que faz com que a verdade que ativamos no corpo, quando intencionalmente revisitamos as sensações de cada um, aconteça como dança? Para Bergson a sensação é realidade:

\begin{abstract}
Quando meus olhos me dão a sensação de um movimento, esta sensação é uma realidade, e algo se passa efetivamente, seja que um objeto se desloque ante meus olhos, seja que meus olhos se movam diante do objeto. Com mais razão ainda estou seguro da realidade do movimento quando o produzo após ter desejado produzi-lo, e o sentido muscular me proporciona a consciência dele. Vale dizer que toco a realidade do movimento quando ele me aparece, interiormente a mim, como uma mudança de estado ou de qualidade (Bergson, 1999, p. 230).
\end{abstract}

Um dos desafios durante a montagem de Lugar nenhum foi encontrar um modo de provocar em cada um dos bailarinos estados de imersão na própria memória e nas experiências vividas por meio da sensação e como encontrar os dispositivos para tal acontecer a cada ensaio ou apresentação. O movimento que surge a partir das sensações "toca a realidade" por meio da consciência, passo a passo. Como fazer esse mergulho sem volta? De pronto eu propus que as histórias que fôssemos lembrar tivessem acontecido quando por volta dos nove anos de idade de cada um de nós. Na Antroposofia ${ }^{2}$ existe uma metáfora que me interessou logo no início da concepção de Lugar nenhum e pensei nas histórias como um gatilho interessante para desenvolver material.

De acordo com essa metáfora antroposófica, quando uma criança nasce é trazida para a terra por um anjo e, com o passar do tempo, a mão que coloca a criança na terra se conecta através de um fio de linha. Ao longo dos anos essa linha vai aumentando a distância entre o anjo e a criança, até que por volta dos nove anos de idade ela se rompe totalmente e, com isso, se desmancha o véu da imaginação que povoa o mundo da criança até então. A partir desse momento a criança passa a ver o mundo somente sem o véu da imaginação e adquire um olhar mais próximo da realidade; é nesse momento que a fantasia perde potência e um olhar mais crítico se constrói. Essa imagem me interessou porque eu queria que as histórias contivessem um aspecto de primeiras experiências de quando nos situamos no mundo de forma mais crítica e mais consciente do meio que nos envolve.

\footnotetext{
2 Antroposofia é uma filosofia que serve como um caminho de conhecimento para guiar o espiritual do ser humano ao espiritual do universo. 0 objetivo do antropósofo é tornar-se mais humano, ao aumentar sua consciência e deliberar sobre seus pensamentos e ações; ou seja, tornar-se um ser espiritualmente livre. Rudolf Steiner (1861-1925), austríaco, é o fundador da Antroposofia.
} 


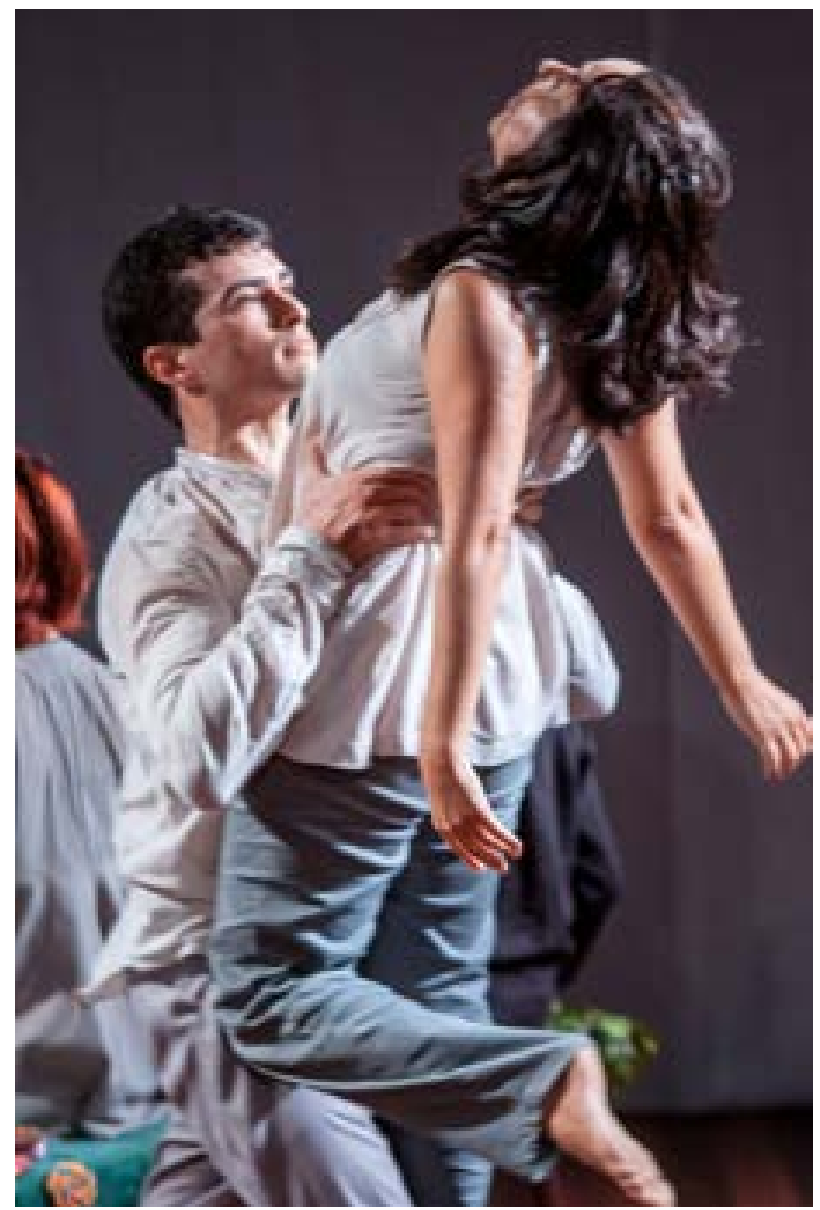

Lugar nenhum - Vicente Mahfuz e Paula Bittencourt Foto: Cristiano Prim

Com as histórias surgiram sensações que a memória daquelas situações evocava, sempre que voltávamos a elas. Quando as sensações encarnam, geram novas sensações, porque a cada instante atualizações das sensações originais são feitas assim como na relação com os outros corpos as impressões se constroem. Assim, a estética passa a ser a própria experimentação da vida como arte, quando a vida se torna, enfim, uma obra de arte como diz Foucault. É como um jogo que é sempre experimentado no sentido de seus limites; estará sempre em vias de transgredir e inverter a regularidade que aceita e com a qual se movimenta; a dança na improvisação de Lugar nenhum se desenrola como um jogo que vai infalivelmente além de suas regras e passa assim para fora no outro. É nesse desvio e mergulho nas sensações que toda a dramaturgia foi se construindo e as imagens, primordialmente internas ao longo do processo de criação, transbordaram para a cena. Fogem de sua origem e encontram novas metáforas que se desenvolvem e transformam-se em outras impressões ou imagens e assim por diante. 


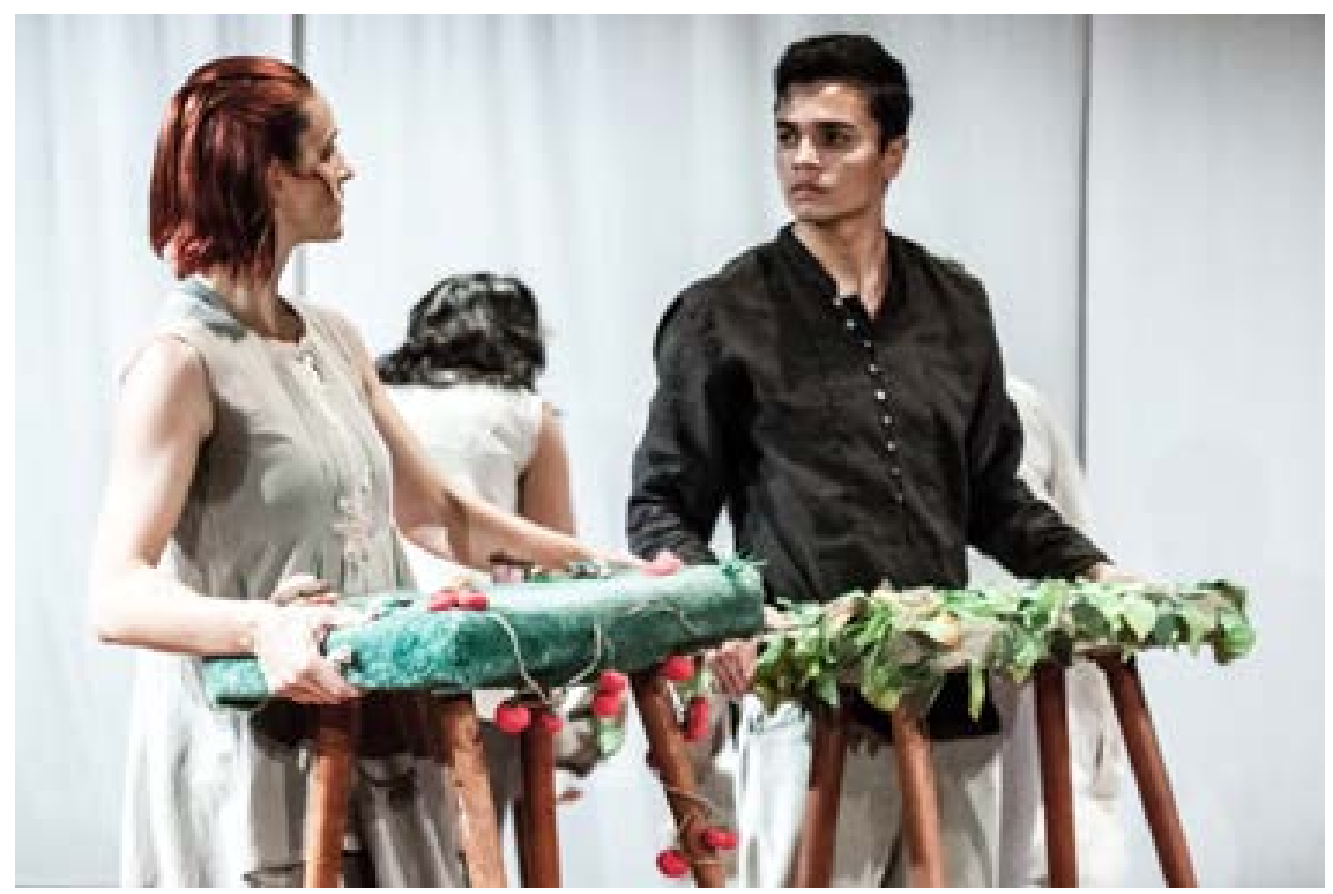

Lugar nenhum - Nastaja Brehsan, Paula Bittencourt e Egon Seidler Foto: Cristiano Prim

Minhas histórias viraram uma recordação de sensações. Hoje elas falam diretamente com o registro dessas sensações em meu corpo, respondendo em imagens, qualidades e padrões de movimento. Quando acesso esses lugares, na cena e com os outros, já não trato mais daquele período, mas revisito em mim, amparado pelo diálogo com o outro, onde e como esses registros reverberam e respondem naquele momento. As histórias foram o ponto chave para as coleções de movimento, junto a padrões que pesquisamos sobre o "eu" (dentro) e o "tu" (fora). Essas fontes são muito ricas por tratarem com a enormidade de sensações, imagens e "estados' que o ser humano tem. Selecionar movimentos parecia reduzir demais esse potencial. Ao mesmo tempo, não selecionar poderia nos levar ao abismo da falta de registro, desenho, consciência dos movimentos. Deste modo, optamos por encontrar coleções de movimento, que se mantivessem abertos independente e que servissem de mote para que o corpo encontrasse e se mantivesse num padrão que respondesse a determinada sensação, história e cena, servindo como base ao improviso nesse território. A partir disto, os encontros surgiram como necessidades desses padrões, como apoio às narrativas, como contribuição estética da diretora e, principalmente, como diálogo, oportunizando tanto opções/aberturas a leitura do espectador sobre a obra quanto recurso criativo e dramatúrgico aos bailarinos (Egon Seidler em depoimento, fevereiro de 2014).

Como pesquisadora e artista, percebo que ao apropriar-me de conceitos originados em outros campos e aplicá-los no processo de montagem como uma ferramenta ou como referência para a invenção de técnicas, confronto-me com o risco. Porém, nesse caso, o Ritornelo me afeta e me comunica exatamente o que concebo em relação à improvisação como aspecto fundamental para o desenvolvimento de pesquisa de movimento em que a sensação é o foco da consciência. Interessa também a partir disso aprofundar questões como a de adentrar territórios desconhecidos e desestabilizar-se de repertórios confortáveis. Um conceito pode provocar, pode originar movimento e pode assim ser transformado em criação; ademais, o Ritornelo e a improvisação fazem parte da mesma rede de ideias, cada um à sua maneira ou em seu campo, no entanto complementares. Não se esgotam e ainda produzem resso- 
nâncias. O Ritornelo é uma espécie de "motivo", aquilo que se repete e se transforma, que sempre retorna e traça um "território" que é já expressão do ritmo de uma variação criadora, de um agenciamento.

Em princípio, Lugar nenhum é sobre afecto e memória e como na dança o evento associa experiências de vida ou, então, sobre como cultivar a lembrança de fatos que se deram num passado que para nós não terminou. $O$ trabalho não foca tanto nas histórias que expressam as lembranças de um vivido, mas sim nas intensidades e nos devires disso que são guardados na lembrança e que, ao serem transformados em dança, se tornam matérias expressivas.

Primeiramente, nos preocupou a capacidade de invocar ou provocar sensações e intensidades e de encarná-las em dança. Depois, a capacidade de "criar repetindo" e de produzir assim um lugar de enunciação singular através de repetições e variações. É, portanto, realizar essa operação tão comum de ativar fragmentos do mundo e da experiência do outro e fazê-los tornarem-se dança.

O pensamento de Deleuze e Guattari (1993) nos forneceu pistas valiosas. Como afirmam esses autores ao tratar do que eles chamaram de "afectos" e "perceptos", aquilo que persiste (uma dor, uma tristeza, uma saudade, uma alegria, uma culpa, uma vergonha, e um momento de abandono) não persiste por causa do cultivo da lembrança. O que perdura são os "blocos de sensações" de dor, de saudade, de perda, de amor, de rejeição, de vergonha e abandono que se colariam a uma lembrança que se expressa na forma de história e que permitem essas sensações retornarem sempre como um "motivo". Exatamente porque, como coloca Bergson ao tratar dos modos de funcionamento da memória e de reconhecimento das imagens, "a lembrança é já uma forma de representação e, como tal, é uma ação" (1999, p. 87).

Acredito que a singularidade de Lugar nenhum reside na forma como trabalhamos as lembranças das histórias pela via das sensações que, por si, impregnaram as narrativas dessas experiências. São tais sensações que são tomadas como um "presente" revivido e refeito a partir, primeiramente, do que Bergson (1999, p. 88) chamou de "imagens-lembranças" - formas primeiras de um registro de memória. No entanto, como afirma Bergson, há também um segundo tipo de memória que se produz a partir da fixação e do alinhamento de uma lembrança no presente. Esse aspecto de continuidade implica uma transformação como outra disponibilidade para a ação sugerida no ato da rememoração. É essa segunda experiência de memória que parece povoar o universo de Lugar nenhum. É exatamente por permitir ver o trabalho realizado com essa segunda forma de memória, atravessada pelos elementos e pelas circunstâncias que a fazem emergir e ser revivida e "agida", como diz Bergson, é que vão ser mobilizados como matéria expressiva e como o "motivo".

Ritornelo, então, como uma espécie de "motivo", aquilo que se repete e muda, que sempre retorna e demarca um "território" que é já expressão do ritmo de uma variação criadora, de um agenciamento. Por sua vez, essa perspectiva coincide com o princípio de "instabilidade do homogêneo" em Gabriel Tarde. Na sua sociologia do infinitesimal, Tarde (2007) se refere a uma "transitividade intrínseca do mundo" como princípio da diferença. Para Tarde, só existem diferença e variação da diferença, sendo que o homogêneo seria apenas um momento dessa variação. 
Encontro similaridades no conceito de "transdução" de Simondon, no qual a questão da variação aparece mais clara. Para Simondon (1964, p. 18), a partir da transdução, "operação física, biológica, mental, social, pela qual uma atividade se propaga gradativamente no interior de um domínio", seria possível produzir passagens de um estado a outro, de um meio a outro, constituindo um novo plano.

No domínio físico, a transdução se efetua sob a forma de repetição progressiva, mas em domínios mais complexos como o vital, por exemplo. Em razão da metaestabilidade, a operação transdutora adquire constante variação, estendendo-se a domínios heterogêneos (Simondon, 1964, p. 18).

Ao relacionar e criar transversalidades destes conceitos para analisar o processo de criação de Lugar nenhum, penso que esse processo se inscreve naquilo que Deleuze e Guattari (1993) chamaram de uma função fabuladora, na qual o que importa não é tanto o que se conta, mas as intensidades que surgem do que é contado. $O$ fundamental é um tornar-se outro na narrativa que não é linear, mas, ainda assim é narrativa. Na fabulação há como que um ultrapassamento, algo que atinge uma qualidade singular, em que uma sensação se torna gesto e o gesto explode aos olhos do espectador como portador de sentido. Segundo Deleuze e Guattarri, isso acontece porque na arte o trabalho intensivo com as formas expressivas permite ao artista "exceder os estados perceptivos e as passagens do vivido", estado esses que eles vão chamar de "perceptos" (1993, p. 222).

A fabulação, operação em que o ato de narrar é parte da produção de um "percepto", o objeto do dispositivo invenção como um dispositivo fabulador ao mesmo tempo cria as condições da narrativa, mas também as deixa livres para irradiar intensidades através das dinâmicas com as matérias expressivas que mobiliza. No processo de montagem de Lugar nenhum, partimos de uma narrativa que foram as histórias sendo contadas; porém, o que permaneceu como estruturante de todo o trabalho foram as sensações que essas histórias evocaram nos corpos, que por sua vez foram fisicamente manifestadas por meio do repertório e das coleções de movimentos e ainda entre as relações que se estabelecem no todo. 


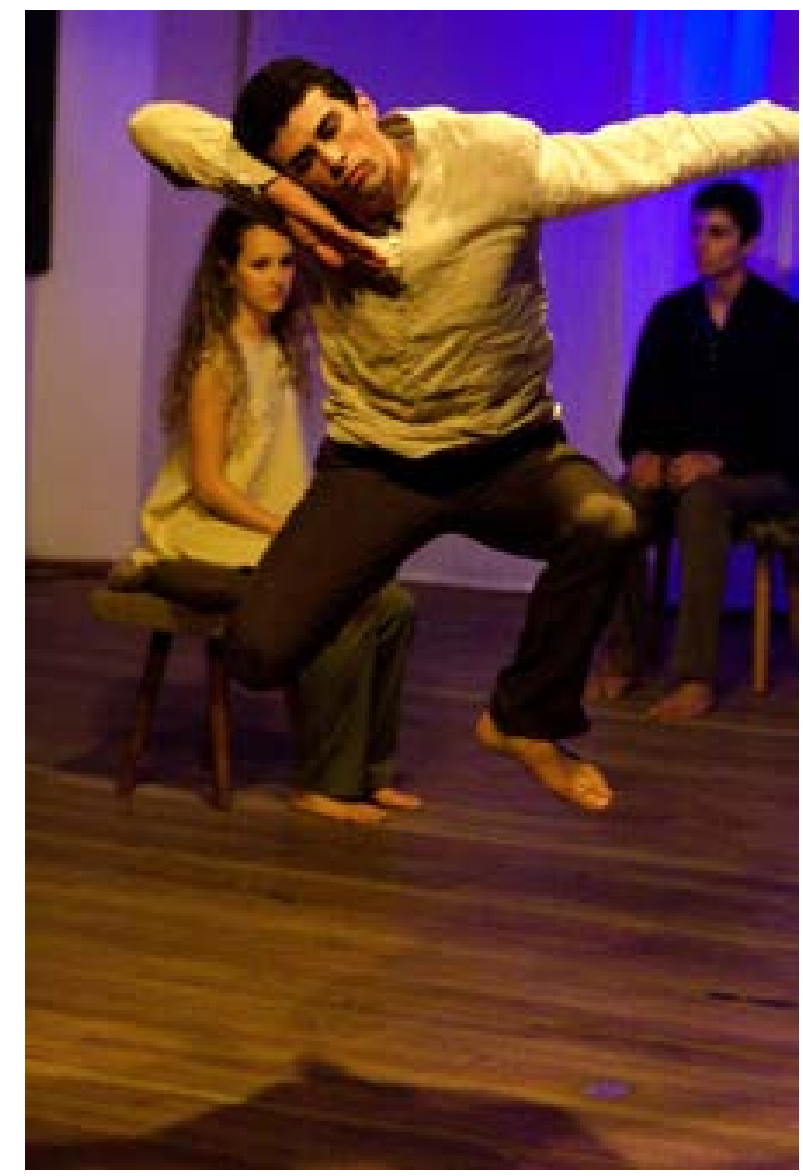

Lugar nenhum - Nastaja Brehsan, Paula Bittencourt e Egon Seidler Foto: Cristiano Prim

Vislumbrar todas as maquinações que nos permitem investir na forma que é dança de nosso trabalho nos traz um frescor e uma intensidade que se faz no instante, em cada ensaio ou em cada apresentação. É também por fazer perceber o que é constitutivo da poética e do potencial estético da pesquisa em seu universo de sentido e de valor que ela funciona como uma espécie de "máquina estética". Para Deleuze e Guattari, o conceito de "agenciamento" envolve modos coletivos de enunciação e, ao mesmo tempo, agenciamentos "maquínicos" de desejo (Deleuze, 1977, p.118). 0 agenciamento é uma espécie de conjunto de engrenagens conectivas que permite a formalização de lógicas sociais e discursivas em torno das quais se organizam coisas, pessoas e ações. É com essa natureza "maquínica" do agenciamento, própria dessa concepção de dispositivo, que os modos e procedimentos de criação do Ronda Grupo e o espetáculo Lugar nenhum se inserem. Para Deleuze e Guattari, pertencemos a certos dispositivos e neles agimos. Com base nesse princípio, penso que é parte de um dispositivo o que podemos definir aqui, nos modos de composição do trabalho, como dispositivo fabulador.

Lugar nenhum é enunciado de agenciamentos de invenção, se inscreve e faz entrar também seus procedimentos, suas técnicas e ações compositivas, as coleções e repertórios de movimento, já engrenagens desse agenciamento. As lembranças acionam esse reviver do passado que, por sua vez, se agencia com a função fabuladora através da dança e das histórias como um "território subjetivo".

Ao longo do processo de montagem, ia ficando claro, ao menos para mim, que o 
que acontecia ali já não era uma simples reprodução do passado por meio da improvisação do material desenvolvido. O que se produziu é algo que já não se confunde com o passado nem se resume a ele, embora exista nele. Se há rememoração, esta se dá mais por meio da convocação e da percepção do vivido, como afirmam Deleuze e Guattari (1993, p. 218). É algo que carrega traços desse vivido, mas que já está para além dele ou que dele independe, os seus "afectos" e "perceptos". Se, por um lado, a memória involuntária quando confrontam as duas sensações separadas no tempo, uma sensação atual e uma sensação passada, mais do que revela a singularidade entre ambas, revela sua natureza ao tornar o antigo contexto inseparável da sensação presente. Ou seja, tornar visível uma afinidade de proximidade que só existe na relação e que, portanto, não está nem na sensação presente nem na sensação passada. É, portanto, a fabulação e não a lembrança que conserva e ao mesmo tempo faz retornar essa sensação como um "motivo". É o Ritornelo que define esse conjunto de matérias de expressão que traçam um território e que se desenvolvem em motivos territoriais, em paisagens territoriais (Deleuze e Guatarri, 1980, p.108).

Para concluir, é por causa da fabulação, mas também da composição de motivos ou paisagens que o repertório para cada cena e suas lembranças adquire uma dimensão particular que intensifica suas potencialidades e os torna tão reais. É assim que cada cena se investe de uma qualidade intensiva que se expressa na forma que é a dança. O que constitui a fabulação são as maquinações, as estratégias de improvisação do repertório e da invenção de novos eventos e materiais em cada apresentação. Toda a cena está estruturada e arredondada por meio de restrições previamente estabelecidas e que se inscrevem nesse território de invenção como ética estabelecida pelo dispositivo fabulador.

\section{Referências}

BERGSON, Henri. Matéria e Memória: Ensaio sobre a relação do corpo com o espírito. São Paulo: Martins Fontes, 1999.

DELEUZE, Gilles; GUATTARI, Felix. Kafka: por uma literatura menor. Rio de Janeiro: Imago, 1977.

O Que é Filosofia? Rio de Janeiro: Editora 34, 1993

Mil Platôs: Capitalismo e esquizofrenia. Vol. 4. São Paulo: Editora 34, 1997.

O Anti-Édipo: Capitalismo e Esquizofrenia. São Paulo: Editora 34, 2010.

NIETZSCHE, Friedrich Wilhelm. A Gaia Ciência. Curitiba: Hemus Distribuidora e Editora S.A., 2002.

SIMONDON, Gilbert. L'Individu et sa Genèse Physicobiologique. Paris: PUF, 1964. 
TARDE, G. Monadologia e sociologia: e outros ensaios. São Paulo: Cosac Naify, 2007.

Recebido em: 12/04/2015 Aprovado em: 16/04/2016 